\title{
NRAS NM_002524.4:C.181C>A
}

National Cancer Institute

\section{Source}

National Cancer Institute. NRAS NM 002524.4:C.181C>A. NCI Thesaurus. Code C98446.

A nucleotide substitution at position 181 of the coding sequence of the NRAS gene where cytosine has been mutated to adenine. 